\title{
Information System in Monitoring Education Students Achievements
}

\author{
Mazin Omar Khairo \\ Management of Information \\ Technology Department \\ Umm Al-Qura University
}

\begin{abstract}
This paper highlights the importance of monitoring studies, one of the most important aspects of quality systems in education, which reflects the degree of actual results achieved by the educational regulations and the systems of education as well. In addition, it is the most advanced instrument for determining the outcome of the awareness of the educational activities and the use of information systems that are entrusted to monitor, as well as to assess the quality of education and information monitoring systems.
\end{abstract}

\section{INTRODUCTION}

We discuss the educational achievements of students that are considered a must for providing the planning and organization for the evaluation activities as well as the process of collecting data and information that are central to the development of both educational institution and information system. The discussion deals with two parts as forth: [1]

1. Part regional: it concerns the collection and processing of information in the region as well as Alsatr and management at the regional level

2. Part schools: it is already implemented in educational institutions. this part should be given more special attention to the central database , which is used to store and collect the information on current activities and results as well as the exchange of questions among themselves at the regional level.[2][3]

What has been taken into account that the monitoring and evaluation of the quality of education has its own development - AIS "Monitoring" functionality is similar to the functions of the regional component of the system. Regional level IP "Portfolio 2.0 was implemented, as a result of completion of the AIS "monitoring". the poor quality and inconsistency of educational channels institutions should be taken into account when designing the school level.

The most appropriate solution is the development of an application - a "thick client", with its own base and ability to sync this data through the mechanism replication. This solution allows users of the OS not only to view the data for the results of the evaluation activities, but also to get of the own application and perform any of the available detection. Regional level, in turn, receives from the school application data concerning teachers and students, made responsible by the OS. Figure 1 schematically illustrates the concept of monitoring the "Portfolio 2".

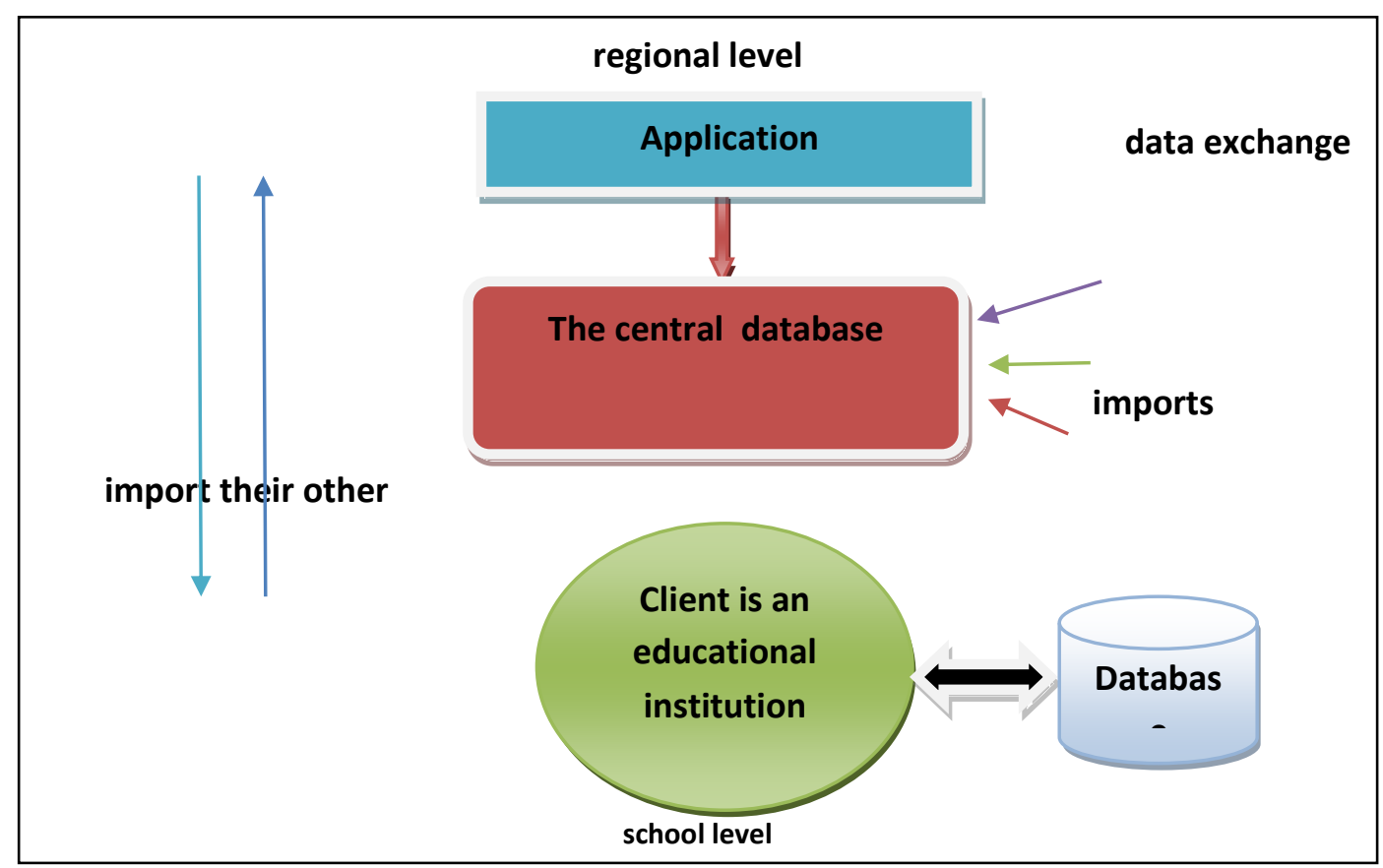

Fig. 1. Levels of interaction scheme IS "Portfolio 2.0 
Applying to the school system level down design, highlighted nine subsystems presented in Figure 2, illustrating their interaction, in particular, the flow of input and output data. Numerals indicate the direction of incoming data and Latin beeches - the result of the system.

Here we can infer that it is planned that the main element of this system is a subsystem of the collection and storage of data, and are followed by databases and gathering information alone and are able to set up and storage and retrieval and also have the ability to remove various information ( this information about educational institutions and students teachers and parallel evaluation activities and results of the discussions ) as also use the following:

1. Use of system -level interaction with the implementation of energy with the regional component of the system to get the information related to the activities on the appointment or measurement and also control the material.

2. Use unit import data, which allows you to get the information from the previous source of the information system without interference from new.

We must determine the unit of organization and assessment activities and unit evaluation activities, which allows an individual set up and received the administration to and conduct assessment activities and shall have the responsibility for the addition and deletion of any involvement of students in any development tasks separately and also separately and impose control staff on materials for educational institutions in order to assess their own and it is at the stage of testing.

One of the most functional and useful modules is TSS subsystem that allows you to build TSS comrade and charts on the results of monitoring procedures or composition classes. As auxiliary to consider administration module and the module reference operating interact directly with the user as well as a regional component. Administration module allows you to set the application to manage inter-layer interaction and user access. Module reference a supportive member.

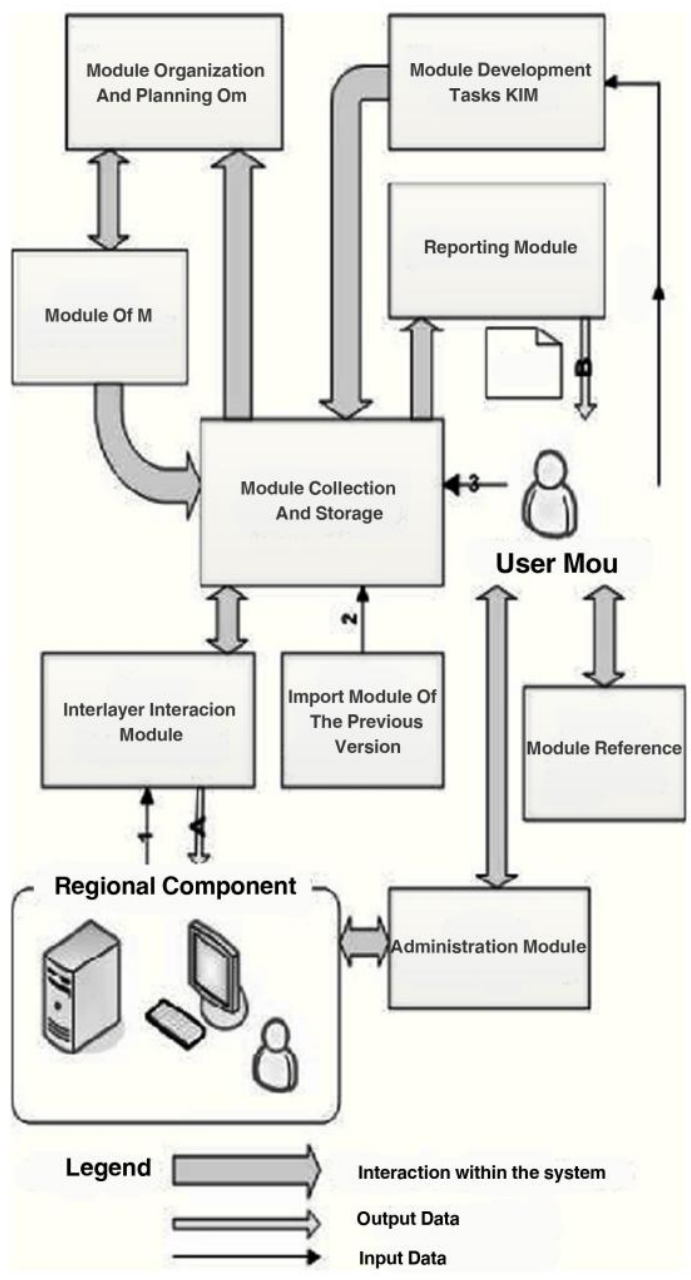

Fig. 2. Decomposition of low-level system modules

And can be seen in the scrutiny of application data in the chart and numbers to indicate the flow of incoming and conclude the following: [3]

1. Data which is obtained from the regional component of the system and also its database, including information on the appointment and measures of the educational institution, as well as the results of monitoring and evaluation activities of State and CT and GIA -9, as well as all the data in the case of the main component of the system.

2. Data that has been imported from the previous version of the information system " file " used in an educational environment

3. Data coming into the system directly from the users of educational institutions, including information about students, teachers, classes.

4. The data coming from the system in the process of staff development and educational institutions to measure and control functions for material evaluation activities.

\section{THE RELATIONSHIP BETWEEN THE MONITOR AND THE CLASSROOM}

Research has established a link between integrating monitoring methods into periodic classroom reviews and the 
later achievement of students involved in the review sessions. Daily, weekly, and monthly reviews can all enhance the learning of[4][5] new material and, if they incorporate questioning and other learning probes, can call attention to areas where re teaching is need [1][2]

The effectiveness of using review sessions to monitor student learning is clearly revealed in the research on the effects of teacher training: teachers trained in methods for conducting periodic classroom reviews which include the use of learning probes had students whose achievement was higher than it was before the teachers had been trained and higher than the achievement of students of untrained teachers. In addition, including monitoring activities in periodic reviews is a built-in feature of such successful programs as and the Exemplary Center for Reading instruction (ECRI) system, as well as being a function carried out by the effective teachers in several comparative observational studies.

\section{FIGURES/CAPTIONS}

Place Tables/Figures/Images in text as close to the reference as possible (see Figure 1). It may extend across both columns to a maximum width of $17.78 \mathrm{~cm}$ (7").

Captions should be Times New Roman 9-point bold. They should be numbered (e.g., "Table 1" or "Figure 2"), please note that the word for Table and Figure are spelled out. Figure's captions should be centered beneath the image or picture, and Table captions should be centered above the table body.

\section{TESTS CLASSROOM}

the evaluation and assessment techniques rushed to them and point out their role in standardized testing, which draws more attention from the research, In addition to, there are tests, classroom and other valuation techniques at the level of chapters with so that the research school located not refer to it with it's well-designed as the programs Test semester have positive relations to refer the students later in this most important and beneficial effects when tests are:[7][8]

1. These tests are administered systematically and repeatedly

2. That these tests are an integral part of the curriculum (aligned with any Courses)

3. That these tests are collected and recorded and immediately returned to the students so that they can correct errors before they become ingrained.

When the study of attitudes toward the test, were found on the students who are tested often, and due to the reactions and attitudes toward the positive tests. And found generally to be regarded as facilitating tests of learning and study, and provide feedback as effective - the result that surprised some researchers, who expected to find more negative attitudes towards student testing.[6]

\section{TEACHERS SKILLS IN MONITORING STUDENT LEARNING}

Given the strong connection between teachers' monitoring of students' learning progress and those students' academic performance, it would be ideal if teachers received thorough training in monitoring and were highly skilled in classroom monitoring practices. Unfortunately, this is not the case. The research on classroom-level monitoring and assessment reveals that:[8][9]
1. While standardized achievement test results are the main focus assessment/evaluation efforts, nearly all important decisions about student placement, instructional pacing and so on are made on the basis of teachers' ongoing classroom monitoring.

2. Many teachers do not: assign homework frequently or regularly, record completion assignments, monitor seat work and check on students' progress, or conduct the kind of questioning that helps to monitor learning.

3. Teachers do not receive adequate pre-service training in conducting formal or informal assessments.

4. Administrative support for and in service training in the skills associated with assessment and monitoring are extremely inadequate.

5. Many teachers are aware that their monitoring skills are inadequate and desire training to expand their capabilities; many others are unaware of the importance of close monitoring of student progress and of their own need for skill development in this area. The research on teachers' decision-making processes confirms this lack of monitoring on the part of many teachers. According to this research, a great many teachers are reluctant to make changes in the instructional strategy or pacing of lessons once these are planned, even when instruction and learning are progressing poorly. To a considerable degree, this improves with experience. Experienced teachers are found to vary teaching strategies in response to student performance cues much more than do novices. Still, monitoring/assessment skills remain an area of inadequate preparation for many teachers.

\section{MEASUREMENT BASED APPROACHES USED TO MONITOR STUDENT PROGRESS?}

This measurement sacrificed the average rate of progress that the student must be maintained in all parts of the world in order to achieve the goal of long-term use of the standard rules of the resolution compared to the teachers and the rates of improvement for teachers in the same direction at about periods specific study to determine whether a student's progress seems insufficient to achieve the overall objective of the eventually, If the direction of progress measurement based approach is more severe than the target line and also raise the goal of the teachers at the end of the year and if it was less intense than the target line to be for teachers to adjust instruction in some ways to better address the needs of individual students and in this way uses teachers measurement -based approach to monitor the students throughout the year and determine the overall effectiveness in educational programs and emphasize the importance of the use of measurement -based approach to monitoring the progress of the Academy and to make amendments to educational programs when necessary, which overtook fully and large compared to students who did not use a measurement -based approach and also provide personal skills, which summarizes the student's level of mastery of skills across the curriculum based measurement units across a given time. [11][12]. 


\section{THE IMPORTANCE OF MONITORING IN E-LEARNING}

Despite the benefits of education based on the Internet can work on the progress of both the student and the teacher and also displays some important challenges any kind of distance learning program offers the high dropout rates of more traditional programs and the nature of education and the nature of distance education can create a sense of isolation in the learners' The students can feel cut off from the coach, it is therefore necessary to provide guidance and assistance of trained just in time for students and also that they provide regular feed-back on these activities. Furthermore, communication among students should also be facilitated and promoted by instructors -who should encourage students' participation in the web spaces devoted to that function Unfortunately it's hard to take a very long time to accurately track all activities carried out by each student in e-learning environment, but it's more complicated to find out the interactions between students or groups of students, particularly between the leaders of the groups, or look at the internal conflicts or breakdowns, which is possible to occur yet too late to manage all these problems, and monitor student activities can help to understand these interactions and predict potential problems, which in turn can give important information about how to organize learning exercises to become more efficient and thus achieve rates or better learning outcomes .

It can also use the monitoring reports by the coaches to track also conduct online learners and group activities in the stages of a certain time with a low degree of activity and will be monitoring the dimension of time and allows for coaches to be aware of groups, students, and thus can be a process monitoring tool for trainers to provide assistance only in time What groups and students as well.

\section{RESULTS}

And thus will benefit from this research show that the main providers of data to information systems is the regional component of the users themselves will analyze the results in:

1. Data sent to the regional component of the system is to collect information about the school, including the preparation of reports and analysis of the behavior of the evaluation activities at various levels.

2. Data provided by users of the system of educational institutions on demand, primarily in the form of technical support services and graphs that contain information about the distribution of students across groups of very detailed technical support services.

And thus efficiency is achieved by using a student's coding and detailed analysis of the functions and characteristics of various information systems and methods of study of measures to evaluate the quality of education.

The structure of information systems implemented by the drafters of publication in the development of intellectual property for the center to monitor and evaluate the quality of education after implementation at the school level are planned and implemented information systems in schools.

\section{REFERENCES}

[1] [Cas00] J. Castro, M. Kolp and J. Mylopoulos. Developing Agent-Oriented Information Systems for the Enterprise, Proceedings of the Second International Conference On Enterprise Information Systems (ICEIS00), Stafford, UK, July 2000.

[2] Brophy, J.E. "Teacher Behavior and Its Effects." JOURNAL OF EDUCATIONAL LEADERSHIP 71 (2001): 733-750.

[3] Fisher, C.W.; C.D. Berliner; N. N. Filby; R. Marliave; L.S. Cahen; and M. M. Dishaw. "Teaching Behaviors, Academic Learning Time, and Student Achievement: An Overview." JOURNAL OF CLASSROOM INTERACTION 17(2005): 2-15.

[4] Nezhnov, P. (2011). SAM - toolkit to assess primary school students' academic achievements. CADMO Innovations in assessment to meet changing needs. ANNO XIX, 1, pp.85-9.

[5] Kardanova E., Gaponova N. New technologies of assessment: School Achievements Monitoring Toolkit // The paper presented at EDULEARN12, Barcelona, Spain, 2012. http://library.iated.org/view/KARDANOVA2012NEW

[6] Business Systems Planning-Information Systems Planning Guide, Application Manual GE20-0627, IBM Corporation; available through IBM branch offices.

[7] Shishoff SE, VA Kal'nei School: monitoring the quality of education., 2000, $241 \mathrm{p}$.

[8] Mayorov, AN Monitoring in Education: Univ. 3rd., Intelligence Center, 2005, $424 \mathrm{p}$.

[9] Adelman, C. 1999. Answers in the tool box: Academic intensity, attendance patterns, and a bachelor's degree attainment. Jessup, MD: U.S. Department of Education Office of Educational Research and Improvement.

[10] Burke, J.C., and H. P. Minassians, ed. 2003. Reporting higher education results: Missing links in the performance chain. New directions for institutional research, no. 116. San Francisco: Jossey-Bass.

[11] Coburn, C. E. 2003. Rethinking scale: Moving beyond numbers to deep and lasting change. Educational Researcher 32 (6): 3-12.

[12] Harvey, W. B. 2003. Minorities in higher education 2002-2003: 20th Annual status report. Washington, DC: American Council on Education.

[13] S. Seufert, U. Lechner, and K. Stanoevska., "A Reference Model for Online Learning Communities". International Journal on E-Learning. 1(1), pp. 43-54, 2002.

[14] Good, T. L., and D.A. Grouws. "The Missouri Mathematics Effectiveness Project: An Experimental Study in Fourth-Grade Classrooms." JOURNAL OF EDUCATIONAL PSYCHOLOGY 71(1979): 355-362.

[15] Medley, D. M. TEACHER COMPETENCE AND TEACHER EFFECTIVENESS: A REVIEW OF PROCESS-PRODUCT RESEARCH. Washington, D.C.: American Association of Colleges for Teacher Education, 1977. (ED 143 629). 